\title{
AVALIAÇÃO DA CONTAMINAÇÃO MICROBIOLÓGICA DE TUBOS DE RESINA COMPOSTA, SERINGAS DE ÁCIDO E PINCÉIS DE PELO MARTA UTILIZADOS EM DIFERENTES RESTAURAÇÕES NA CLÍNICA ODONTOLÓGICA*
}

\section{EVALUATION OF MICROBIOLOGICAL CONTAMINATION OF TUBES OF COMPOSITE RESIN, SYRINGES OF ACID AND FUR BRUSHES USED IN DIFFERENT DENTAL RESTORATIONS.}

\author{
Maria Eni Batista" \\ Paola Souza Gomes"* \\ Maria Rita Lopes da Silva de Freitas \\ Maria Eugênia Alvarez-Leite*****
}

\begin{abstract}
RESUMO
Introdução: A técnica incremental restauradora, com aplicação de porções de resina composta nos preparos cavitários odontológicos, pode gerar o risco de infecção cruzada, uma vez que a resina é retirada de um mesmo tubete, que é utilizado em vários pacientes diferentes. Esse problema se agrava em clínicas acadêmicas de Odontologia, onde esses artigos são compartilhados por todos os alunos. De forma similar, o pincel de pelo Marta e a seringa para aplicaçã̃o de ácido também podem apresentar microrganismos adquiridos durante o atendimento restaurador. Método: Diante desses eventuais riscos, este trabalho teve como propósito verificar a contaminação microbiológica de tubetes de resina, seringas de ácido e pincéis de pelo Marta através de amostras coletadas nas clínicas de Odontologia de uma universidade privada. Foram utilizados 23 tubetes de resina, 13 pincéis de pelo Marta e 13 seringas de ácido, divididos entre grupos caso e controle. Realizou-se o processamento através da fricção com "swab" estéril, nas partes externas das seringas e dos tubetes e da imersão dos pelos dos pincéis em solução salina por um minuto. Os espécimes foram semeados em caldo BHI e, após o crescimento, foram executadas diluições seriadas e semeaduras em meio Ágar Mitis salivarius, BHI e Hipertônico Manitol. Resultados e conclusões: Através da avaliação microbiológica qualitativa (avaliação da presença de turbidez) e quantitativa (número de UFC) de microrganismos, observou-se a contaminação de $50 \%$ dos pincéis e $46,15 \%$ dos tubetes, nos grupos caso; enquanto nas seringas com ácido e em todos os artigos do grupo controle não houve crescimento de microrganismos.
\end{abstract}

DESCRITORES: Contaminação, Resinas compostas, Tubetes de resina, Pincel pelo Marta, Dentística.

\section{ABS TRACT}

Introduction: The layering composite technique which consists of applying small amounts of composite resin in the tooth cavity preparation, can generate the risk of cross infection. The contamination is due to removal of the composite of a single tube which, in turn, is used in many different patients. This problem increases in graduate dental clinics where many students practice together the technique of teeth restoration, using composite tubes that are shared by all them. The use of fur brushes and syringes for applying acid in different patients are also tools that may present microorganisms acquired during restorative procedures. Method: Considering this eventual risk, this study intended to verify the microbiological contamination of tubes of composite resin, syringe of acid and fur brushes in samples collected from dental clinics in a private university. The items used in this experiment were 23 tubes of resin, 13 fur brushes and 13 syringes of acid, and they were divided into case groups and control groups. Samples were collected with saline wetted swabs rubbed over the surfaces of each syringe and composite tube. The fur brushes were immersed in saline for $1 \mathrm{~min}$. Later, the swabs were immersed in BHI broth and serially diluted samples were spread on Mitis salivarius, BHI and Mannitol Salt agar plates. The results were obtained by microbiological qualitative and quantitative analysis (CFU). Conclusion: Contamination was found in $50 \%$ of the fur brushes and $46,15 \%$ of the composite tubes. No microorganisms were found in the serynges of acid. In the control groups, no contamination was found.

DESCRIPTORS: Contamination, Composite resins, Tubes of composite resin, Fur brushes, Dentistry.

* Trabalho de pesquisa apresentado ao Programa de Iniciação Científica da FUNDAÇÃo DE AMPARO À PESQUISA DO ESTADO DE MINAS GERAIS PROBIC/FAPEMIG - (PROBIC-no. 2011/6061-1S) como parte do Programa de Graduação em Odontologia da Pontifícia Universidade Católica de Minas Gerais.

** Graduanda do Departamento de Odontologia da PUC Minas (DOPUCMinas) / email: marenibat@hotmail.com

*** Graduanda do Departamento de Odontologia da PUC Minas (DOPUCMinas) / email: paola_souzagomes@hotmail.com

**** Mestre em Clínicas Odontológicas pela FOPUC Minas; Professora Assistente do Departamento de Odontologia da PUC Minas (DOPUCMinas) / email: mritaf2002@yahoo.com.br

***** Mestre e Doutora em Microbiologia pelo ICB-UFMG; Professora Adjunta do Departamento de Odontologia da PUC Minas / email: alvarezleite@uol.com. br 
BATISTA ME

GOMES PS

FREITAS MRLS ALVAREZ-LEITE ME

AVALIAÇÃO DA

CONTAMINAÇÃO MICROBIOLÓGICA

$D E$ TUBOS DE RESINA COMPOSTA,

SERINGAS DE

ÁCIDO E PINCÉIS

DE PELO MARTA

UTILIZADOS EM

DIFERENTES

RESTAURAÇÕES

NA CLINICA

ODONTOLÓGICA

\section{6}

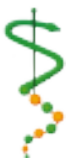

REV, ODONTOL,

UNIV. CID, SÃO

PAULO

2013; 25(2): 115 -

25, MAIO-AGO

\section{IN TRO DUÇÃO}

A cavidade oral é um ecossistema que abriga vários microecossistemas, onde se encontra uma microbiota altamente diversificada e de grande complexidade, que é adquirida desde o nascimento a partir da microbiota cervical da mãe. Primeiramente, ocorre a implantação de espécies pioneiras com pouca diversidade. Em seguida, através de sucessões ecológicas, ocorre aumento do número, da proporção e da diversidade; e assim, na idade adulta, a microbiota oral já está estabilizada em número (aos bilhões) e espécies (já ultrapassando 700 espécies). Esta se mantém em equilíbrio dinâmico apresentando caráter anfibiôntico, no qual, quando em relacionamento estável, beneficia o hospedeiro. Entretanto, se ocorrer um desequilíbrio provocando o crescimento excessivo desses microrganismos residentes, eles passam a gerar muitos metabólitos nocivos causando doenças infecciosas como cárie, periodontite, halitose e até câncer bucal ${ }^{1}$.

Procedimentos clínicos realizados pelo dentista podem gerar este desequilíbrio, ocasionando alteração da microbiota residente ou a colonização eventual de microrganismos exógenos que, por sua vez, podem causar danos. Dentre eles, encontra-se o procedimento restaurador estético com resina, amplamente utilizado pelos cirurgiões-dentistas ${ }^{2}$. A aplicação da resina composta, quando devidamente executada, proporciona uma relação imperceptível entre o dente natural e o dente tratado. Por isso, esse material é usado para restituir a estética e funcionalidade dos elementos dentários ${ }^{3,4}$.

Apesar das inúmeras vantagens da utilização desse material restaurador, a execução de sua técnica é crítica quanto à possibilidade de infecção cruzada, pois há o amplo manuseio dos tubos de resina composta, geralmente sem nenhuma proteção do mesmo, predispondo esse material à contaminação por aerossóis durante o preparo cavitário ou à contaminação de pacientes pelo manuseio indevido do profissional e pelo uso comum de um mesmo tubo em restaurações diferentes.

O método de esterilização mais difun- dido e adequado para artigos odontológicos é o calor úmido (vapor d'água sob pressão). Um ciclo completo e seguro de esterilização na autoclave constitui-se de aquecimento, esterilização e secagem, com a temperatura do processo a vapor (autoclave) variando entre $121^{\circ}$ a $134^{\circ}$ Celsius, conforme os materiais a serem esterilizados. Entretanto, esse método altera as propriedades da resina e, por isso, não é possível ser utilizado nos tubetes, o que representa um risco potencial de infecção cruzada, pois a cavidade bucal é um ambiente repleto de microrganismos que podem aumentar a incidência de doenças graves e transmissíveis. O emprego de álcool a $70 \%$ através de uma leve fricção do tubete é o método alternativo realizado para minimizar os riscos de contaminação ${ }^{5}$.

Nos procedimentos odontológicos, os agentes infecciosos podem ser transmitidos de três maneiras: contato direto, contato indireto e através dos respingos de sangue e saliva emitidos pelo uso de aerossóis da caneta de alta rotação. No contato direto, a transmissão ocorre em consequência do contato físico entre o reservatório microbiano original e o receptador. Na forma indireta, as mãos do profissional contendo saliva e sangue são responsáveis por contaminar a zona operatória e seu entorno ${ }^{6}$.

O risco de contaminação da resina composta ocorre, especialmente, porque a prática restauradora com esse material é cada vez mais frequente, devido à preocupação por parte de muitos profissionais e pacientes com relação à estética dos dentes. O grande problema ocorre porque a técnica incremental da resina composta consiste na aplicação de pequenas partes desse material no preparo cavitário e frequente utilização de um mesmo tubete em vários pacientes diferentes. Como não é possível realizar a esterilização desse objeto, pode ocorrer a transmissão de vários microrganismos entre pacientes, trazendo, muitas vezes, sérias complicações tanto para o paciente quanto para o profissional. Particularmente nas clínicas acadêmicas de Odontologia, onde há vários estudantes executando a mesma técnica restauradora, utilizando tubetes de resina 
que são compartilhados por todos, agrava-se o risco de transmissão microbiana.

Tal como a técnica incremental da resina e seu manuseio por diversos alunos, a utilização do pincel de pelo Marta e da seringa para aplicação de ácido nos preparos cavitários é também procedimento passível de gerar infecção cruzada. Esses pincéis e seringas também não são esterilizados e, por isso, podem apresentar microrganismos adquiridos durante $\mathrm{O}$ atendimento restaurador. Ademais, são utilizados junto à resina composta e, de forma similar, em restaurações de pacientes diferentes.

Infecção cruzada é a passagem de agente etiológico de doença, de um indivíduo para outro susceptível. No consultório odontológico, são quatro as vias possíveis de infecção cruzada: do paciente para o pessoal odontológico; do pessoal odontológico para pacientes; de paciente para paciente através do pessoal odontológico; e de paciente para paciente por intermédio de agentes como instrumentos, equipamentos e pisos. Testes microbiológicos demonstraram que todos os instrumentos dispostos na bandeja, para cirurgia ou outro tratamento qualquer, ficam contaminados após atendimento, mesmo aqueles que não foram usados. Esses instrumentos são contaminados pela deposição de aerossóis constituídos pelo sangue, saliva, tecidos e fluidos orgânicos entre outros ${ }^{7}$.

Analisando a contaminação da cadeira odontológica através da utilização de placas contendo ágar-sangue, Almeida e Jorge $^{8}$ (2002), comprovaram que ocorre aumento na quantidade de microrganismos encontrados na superfície da cadeira odontológica após o atendimento dos pacientes, comprovando a ocorrência de contaminação microbiana através dos aerossóis. Vários itens do consultório tornam-se contaminados com a microbiota proveniente da pele, dos cabelos e da cavidade bucal. Os resultados demonstraram que a média da quantidade de microrganismos encontrados após o atendimento do paciente foi estatisticamente superior ao controle.

Montenegro et al.2 (2004) avaliaram a contaminação da parte externa dos tubos de resina composta nas clínicas de uma faculdade de Odontologia, após a manipulação desses tubos durante os procedimentos de dentística restauradora. Para tanto, foram utilizados swabs estéreis umedecidos e friccionados na parte externa do tubo, na tampa e na ponta da rosca. Os espécimes foram então inoculados em caldo BHI e incubados em estufa bacteriológica a $37^{\circ} \mathrm{C}$. Após 24 horas, $68 \%$ das 50 amostras coletadas apresentaram turvação (crescimento bacteriano), demonstrando elevada contaminação.

Pinheiro e Castro ${ }^{9}$ (2009) quantificaram o total de bactérias viáveis antes e após a utilização do equipamento odontológico e periféricos. Os autores observaram um aumento significativo do total de bactérias viáveis antes e após o atendimento com a utilização das canetas de alta rotação e a da cuspideira, principalmente. A incorporação de barreiras de proteção (como o filme de PVC, p. ex.) não impediu o aumento significante da contaminação. Nesse estudo, os pesquisadores observaram a presença de hemoglobina em amostras coletadas dos aerossóis durante procedimentos dentários, resultando na possibilidade de transmissão do vírus da hepatite B, hepatite C e HIV entre profissional e paciente.

O estudo realizado por Cecchin et al. ${ }^{10}$ (2009) investigou a contaminação de várias superfícies antes e após o atendimento de pacientes nas clínicas odontológicas de uma universidade, coletando amostras de diversas superfícies e objetos. Após semeadura em meio de cultura TSA e incubação a $37^{\circ} \mathrm{C}$, por 48 horas, foi feita a contagem, em número de UFC/ml. Nos resultados, verificou-se a presença de contaminação de várias superfícies, inclusive nos tubos de resina composta.

Para avaliar a contaminação microbiológica dos tubos de resina composta utilizados na clínica odontológica, Correia ${ }^{11}$ (2009) coletou amostras da parte externa de dez tubos, utilizando-se de swabs estéreis. Os espécimes foram introduzidos em tubos de ensaio contendo $3 \mathrm{ml}$ de meio de cultura BHI líquido para transporte e, posteriormente, semeados em placas de Petri contendo meio ágar BHI. O autor concluiu que as mãos do cirurgião-dentista podem carrear microrganismos, favorecendo a
BATISTA ME

GOMES PS

FREITAS MRLS

ALVAREZ-LEITE ME

AVALIAÇÃO DA

CONTAMINAÇÃO

MICROBIOLÓGICA

DE TUBOS DE

RESINA COMPOSTA,

SERINGAS DE

ÁCIDO E PINCÉIS

DE PELO MARTA

UTILIZADOS EM

DIFERENTES

RESTAURAÇÕES

NA CLIINICA

ODONTOLÓGICA

117

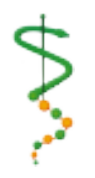

ReV. OdOntOl.

Univ, Cid, São

Paulo

2013; 25(2): 115-

25, MAIO-AGO 
BATISTA ME

GOMES PS

FREITAS MRLS

ALVAREZ-LEITE ME

AVALIAÇÃO DA

CONTAMINAÇÃO

MICROBIOLÓGICA

DE TUBOS DE

RESINA COMPOSTA,

SERINGAS DE

ÁCIDO E PINCÉIS

DE PELO MARTA

UTILIZADOS EM

DIFERENTES

RESTAURAÇÕES

NA CLINIICA

ODONTOLÓGICA

$118 \ldots$

REV, ODONTOL,

UNIV. CID, SÃO

PAULO

$2013 ; 25(2): 115-$

25, MAIO-AGO infecção cruzada através da manipulação direta do tubo de resina composta.

A contaminação dos tubos de resina composta utilizados na clínica odontológica foi verificada por Aleixo et al. ${ }^{12}$ (2010) a partir da utilização de 60 tubos de resina composta usados nas clínicas odontológicas da Faculdade São Lucas, Porto Velho-RO. Os tubos foram divididos em 3 grupos: em uso, armazenados e desinfetados com álcool a 70\%. Foi observada intensa contaminação nos tubos armazenados e em uso. Já os tubos desinfetados com álcool a $70 \%$ mostraram menor contaminação microbiana.

Segundo o trabalho realizado por Almeida et al. ${ }^{13}$ (2010) que avaliaram o nível de contaminação de resinas compostas utilizadas em consultórios odontológicos, $80 \%$ das amostras coletadas encontravam-se contaminadas por estafilococos coagulase-negativo $(47,2 \%)$, estafilococos coagulase-negativo em associação com Bacillus (16,3\%), Bacillus sp (12,7\%) e Aspergillus sp (3,6\%). Por outro lado, o grupo-controle não apresentou crescimento microbiano. A partir dos resultados obtidos, os autores concluíram que as bisnagas de resina composta podem se tornar uma fonte de infecção cruzada e que medidas de biossegurança precisam ser adotadas durante a sua manipulação.

A análise realizada por Ferraz et al. ${ }^{14}$ (2010) verificou a contaminação de bisnagas de resinas compostas foto-ativadas ou não. Para tanto, as amostras foram coletadas friccionando-se swabs estéreis por toda a superfície das bisnagas durante 1 minuto e, posteriormente, os espécimes foram semeados em caldo BHI. As coletas foram realizadas durante o uso clínico das resinas; antes de sua ativação, e após serem ativadas com LED e luz halógena, Num dos grupos, os tubetes foram previamente desinfetados com álcool a $70^{\circ}$. Os resultados comprovaram a ocorrência de contaminação da superfície externa das bisnagas de resinas compostas em todas as amostras coletadas, inclusive nos tubetes que sofreram desinfecção por álcool a $70^{\circ}$.

Sobre a contaminação em tubos de resina composta manipulados sem barreira de proteção, Cardoso et al. ${ }^{15}$ (2010) apre- sentaram uma pesquisa feita numa clínica/ escola de Odontologia, durante nove sessões clínicas, utilizando dez tubos de resinas, sendo um deles, o controle negativo, pois foi avaliado sem manipulação prévia. Posteriormente, os tubos foram incubados durante 24 horas em água peptonada tamponada. Após diluições seriadas de até $10^{-2}$, os espécimes foram semeados em ágar Manitol Salgado e ágar BHI. Os resultados confirmaram a contaminação dos tubos durante os procedimentos clínicos, desde a primeira sessão de manipulação e mostraram ainda que, a cada nova sessão de manipulação, foi observada uma maior contagem total de microrganismos.

Krieger et al. ${ }^{16}$ (2010) demonstraram a importância de se ficar atento ao fato de que todo e qualquer procedimento odontológico envolve algum tipo de contaminação, pois o meio bucal é rico em microrganismos e, dessa forma, a saliva é a principal fonte de transmissão de patologias. Sabe-se que são necessárias minúsculas quantidades de sangue ou saliva, sobretudo de fluido gengival $(0,00004 \mathrm{ml})$, para que ocorra a transmissão da hepatite B. Os riscos de contaminação, durante e após procedimentos invasivos, são de $30 \%$ a $50 \%$.

Pinelli et al. ${ }^{17}$ (2011) enfatizaram a necessidade de se aperfeiçoar as estratégias educacionais, com intuito de motivar a fiel adesão às normas de biossegurança, essenciais no trato de pacientes odontológicos, visto que, dentro da Odontologia, os acadêmicos têm sido apontados como o grupo para o qual a educação em biossegurança e o controle de infecção cruzada são imprescindíveis para o correto treinamento e cumprimento dos procedimentos. Entretanto, a literatura sobre biossegurança e Odontologia tem mostrado por meio de análise quantitativa - metodologia aplicada à maioria desses estudos - que o grau de obediência do próprio profissional aos protocolos é variável, seja para medidas de proteção individual, seja para medidas coletivas.

Portanto, diante de eventuais riscos, este trabalho teve como objetivos avaliar, quantitativa e qualitativamente e por cultura microbiológica, a ocorrência de contaminação de artigos utilizados em 
Dentística (tubetes de resina, pincéis de pelo Marta e seringas de ácido), a partir de amostras coletadas nas clínicas de graduação do Departamento de Odontologia de uma universidade privada.

\section{MÉTODOS}

Avaliação microbiológica da contaminação dos tubetes de resina, pincel pelo Marta e seringas de ácido.

1. Seleção dos grupos

Os espécimes clínicos foram obtidos a partir de 23 tubetes de resina, 13 pincéis pelo Marta e 13 seringas de ácido, utilizados nos procedimentos restauradores; destes, 10 tubetes, 8 seringas e 8 pincéis pelo Marta foram levados, previamente, à cavidade oral e mantidos durante o atendimento clínico de pacientes. Cada um desses 26 artigos foram avaliados com swab estéril ou através de imersão. As superfícies avaliadas com swab foram a ponta ejetora da seringa para ácido e toda a extensão dos tubos de resina (da ponta de rosca até a asa); já no pincel de pelo Marta foi realizada a imersão da região de pelos (ponta ativa). O restante (grupo-controle) dos artigos $(n=20)$ teve o mesmo processamento sem, entretanto, ter sido utilizado em pacientes.

\section{Amostra}

Grupo-Caso: vinte e nove artigos: 13 tubos de resina composta, 8 seringas de ácido, 8 pincéis pelo Marta utilizados no curso de Odontologia (Figura 1 - A e B)

Grupo-Controle: vinte artigos: dez tubos de resina composta, cinco pincéis de pelo Marta e cinco seringas de ácido, não utilizados previamente pelos alunos.

3. Coleta e processamento dos espécimes clínicos - Avaliação microbiológica qualitativa e quantitativa.

No caso dos grupos experimentais, ao final de cada atendimento clínico, os artigos foram transportados imediatamente, acondicionados em caixas estéreis, para o laboratório de Microbiologia e processados em um tempo não superior a $20 \mathrm{mi}$ nutos.

A manipulação de todos os tubos, pincéis e seringas foi realizada sob condições assépticas. No caso do grupo-controle, os artigos foram retirados do invólucro do fabricante em ambiente estéril, em câmara de fluxo laminar, e acondicionados em caixa plástica com tampa, esterilizada previamente.

As coletas foram iniciadas através da fricção de um swab umedecido com solução salina estéril, por um minuto, nas partes externas dos tubos de resina e seringa para ácido, em área previamente de-

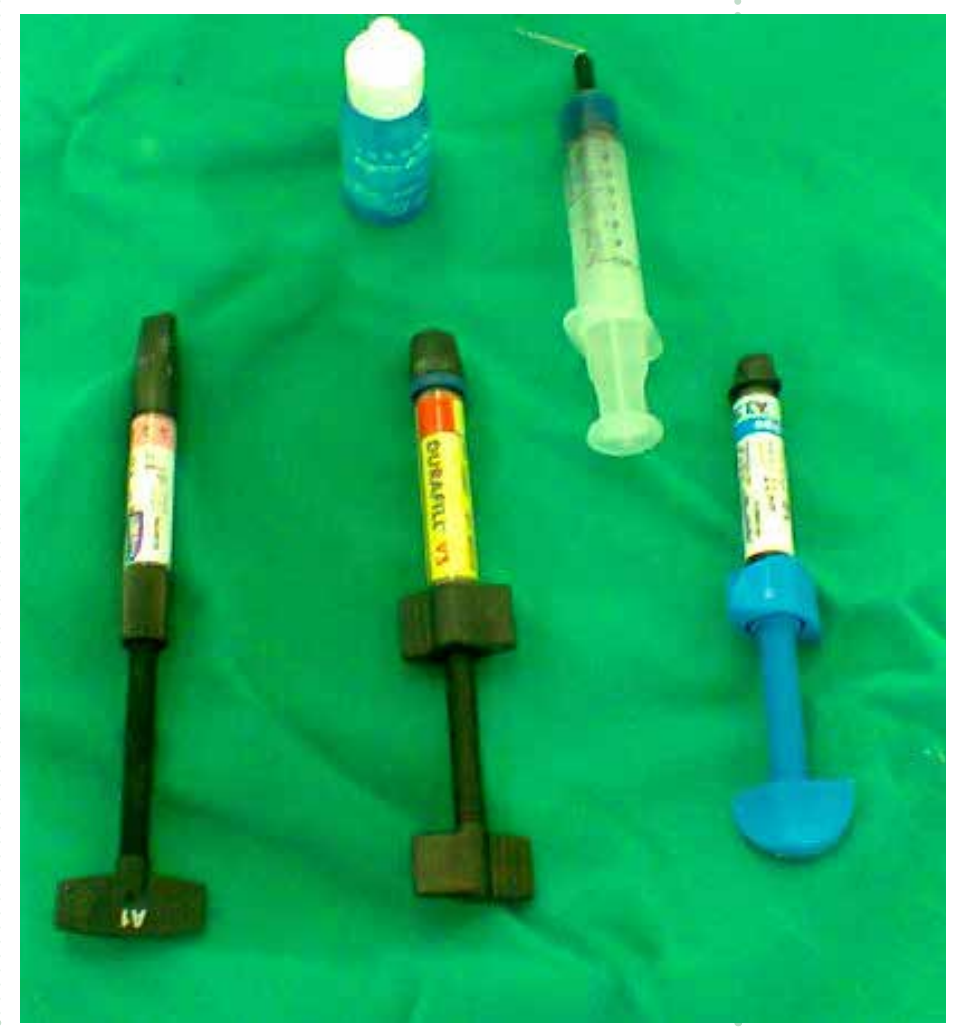

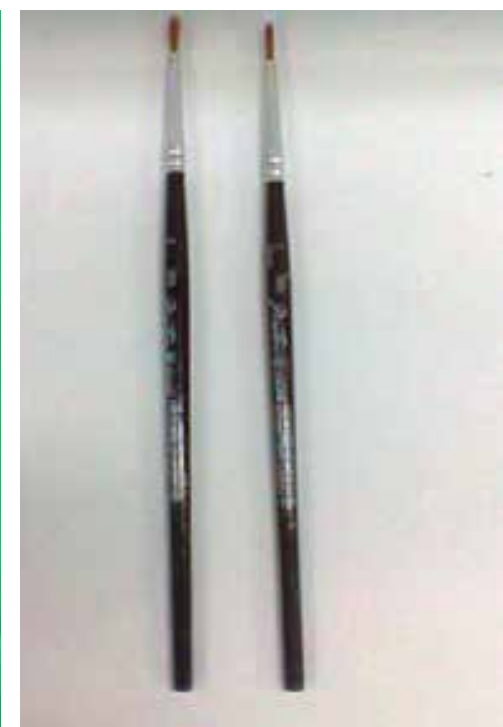

Figura 1 - Tubetes de resina, seringas de ácido $(A)$ e pincéis pelo Marta (B) do Grupo Caso (utilizados pelos acadêmicos, nas clínicas odontológicas).
BATISTA ME

GOMES PS

FREITAS MRLS

alvarez-LEITE ME

AVALIAÇÃO DA

CONTAMINAÇÃO

MICROBIOLÓGICA

DE TUBOS DE

RESINA COMPOSTA,

SERINGAS DE

ÁCIDO E PINCÉIS

DE PELO MARTA

UTILIZADOS EM

DIFERENTES

RESTAURAÇÕES

NA CLIINICA

ODONTOLÓGICA

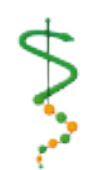

REV. OdONTOL.

UNIV, CID, SÃO

PAULO

2013; 25(2): 115 -

25, MAIO-AGO 
BATISTA ME

GOMES PS

FREITAS MRLS ALVAREZ-LEITE ME

AVALIAÇÃO DA

CONTAMINAÇÃO

MICROBIOLÓGICA

DE TUBOS DE

RESINA COMPOSTA,

SERINGAS DE

ÁCIDO E PINCÉIS

DE PELO MARTA

UTILIZADOS EM

DIFERENTES

RESTAURAÇÕES

NA CLINIICA

ODONTOLÓGICA

120

REV, ODONTOL

UNIV, CID, SÃO

PAULO

2013; 25(2): 115 -

25, MAIO-AGO marcada. Em seguida, os espécimes foram imersos e mantidos sob agitação por um minuto, em tubos contendo caldo Brain Heart Infusion - BHI (Difco $\left.{ }^{\mathrm{TM}}\right)$.

Para a avaliação qualitativa da contaminação foi utilizada, como parâmetro, a presença ou ausência de turbidez nos tubos com o caldo BHI contendo os artigos. Foram considerados não contaminados aqueles que se mantiveram em tubos com o caldo BHI límpido, pelo tempo do experimento, em condições de aerobiose. Nos casos em que houve crescimento dos microrganismos nos tubos (presença de turvação), foram avaliados os níveis de contaminação, através da semeadura em meios sólidos específicos. Para tanto, foram realizadas diluições seriadas e, em seguida, alíquotas de $0,1 \mathrm{ml}$ foram semeadas em ágar enriquecido $\mathrm{BHI}$ (Difco ${ }^{\mathrm{TM}}$ ), Hipertônico Manitol (Difco ${ }^{\mathrm{TM}}$ ) para a recuperação de microrganismos do gênero Staphylococcus e Mitis salivarius (Di$\mathrm{fCO}^{\mathrm{TM}}$ ) para o isolamento de estreptococos orais.

O pincel de pelo Marta foi processado através da imersão da ponta ativa, por um minuto, em solução salina. Os procedi-

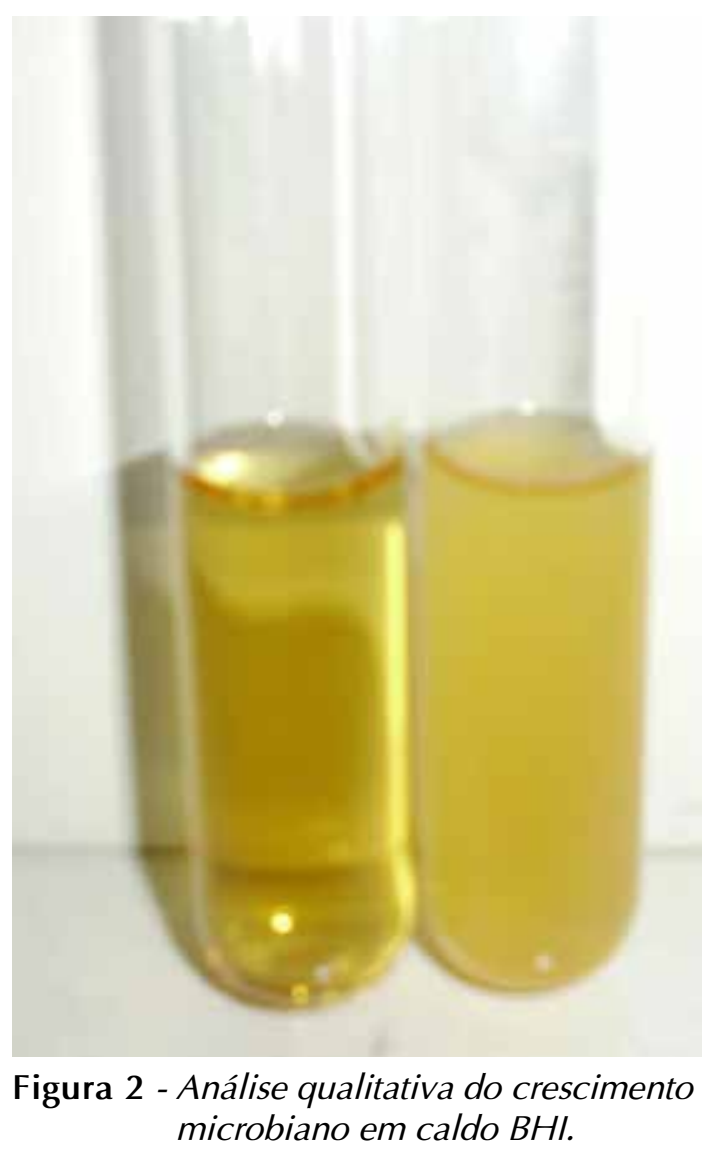

mentos qualitativos e quantitativos foram então executados de forma semelhante aos tubos de resina e seringas para ácido.

Todos os conjuntos dos grupos experimentais e controle foram incubados a $35,5^{\circ} \mathrm{C}\left( \pm 2^{\circ} \mathrm{C}\right)$ em estufa bacteriológica, por 72 horas. A análise do crescimento microbiano foi feita através da presença (crescimento positivo de microrganismos) ou ausência de turvação (crescimento negativo de microrganismos) dos caldos $\mathrm{BHI}$ (Figura 2).

A avaliação microbiológica quantitativa foi verificada através da contagem total de microrganismos (número de UFC) nos meios de cultura BHI, Hipertônico Manitol e Mitis salivarius (Figuras 3, 4 e 5).

\section{RESULTADOS}

Foi realizada a análise de 20 itens no grupo-controle e 29 itens no grupo caso, sendo: 10 tubetes de resinas do grupo-controle, 13 tubetes de resinas do grupo

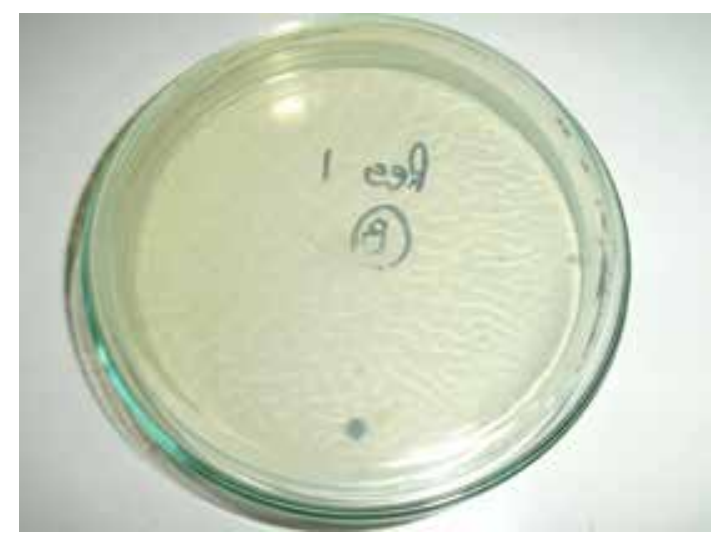

Figura 3 - Avaliação quantitativa da contaminação microbiana no meio de cultura BHI (número de UFC)

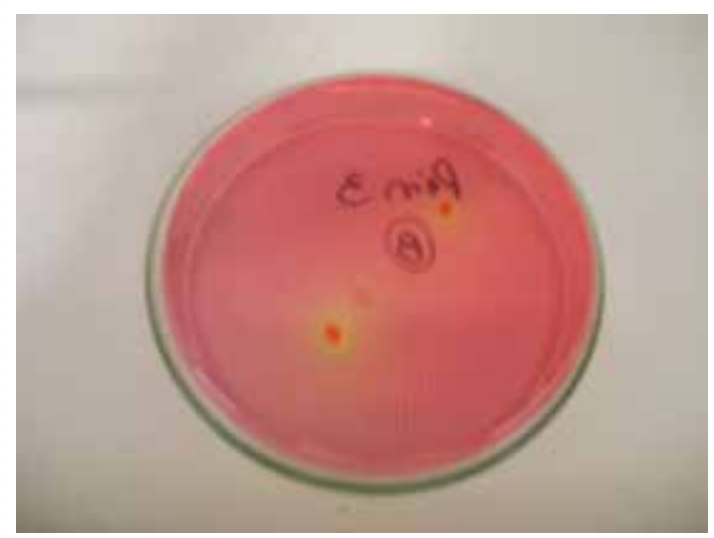

Figura 4 - Avaliação quantitativa da contaminação microbiana no meio de cultura Hipertônico Manitol (número de UFC). 


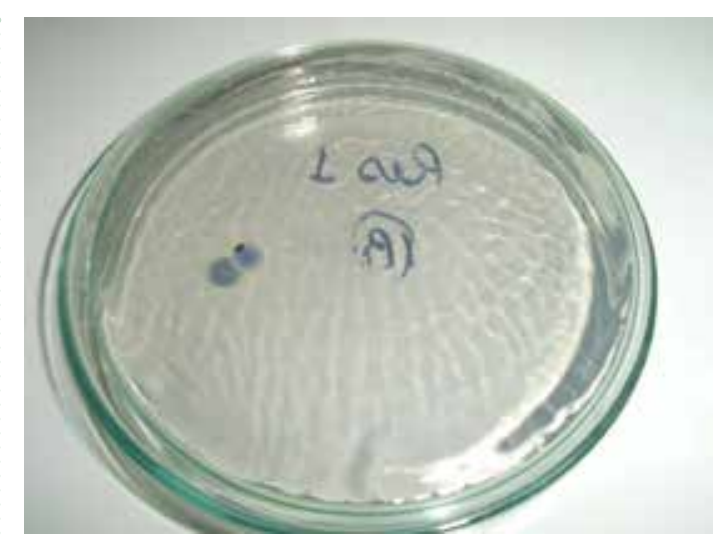

Figura 5 - Avaliação quantitativa da contaminação microbiana no meio de cultura Mitis salivarius (número de UFC).

caso, 5 pincéis de pelo Marta do grupo-controle, 8 pincéis de pelo Marta do grupo-caso, 5 seringas de ácido do grupo-controle e 8 seringas de ácido do grupo-caso. Os artigos coletados no grupo-caso incluíram itens que foram utilizados sob a técnica de isolamento absoluto e isolamento relativo do campo operatório. Os resultados foram observados a partir da turvação do caldo BHI e dos crescimentos coloniais nos meios de cultura: ágar Mitis salivarius, ágar Hipertônico manitol e ágar BHI.

O maior índice de contaminação microbiológica foi encontrado nos grupos caso do pincel de pelo Marta com metade dos tubetes contaminados, seguido pela contaminação do tubete de resina, com $46,1 \%$. Observou-se um número significativo de contaminação nos pincéis pelo Marta, principalmente nos itens que foram utilizados sob a técnica de isolamento relativo do campo operatório. Foram recuperados microrganismos em todos os tipos de meios de cultura utilizados, com maior destaque para o ágar $\mathrm{BHI}$, seguido pelo meio Mitis salivarius e, em menor quantidade, no meio Hipertônico Manitol (Tabela 1). De maneira semelhante, nos tubetes de resina, a contaminação também foi significativa, particularmente, naqueles itens manuseados sob a técnica de isolamento relativo do campo operatório (Tabela 2).

O grupo-controle apresentou números reduzidos de contaminação tanto nos tubetes de resina quanto nos pincéis pelo Marta; nestes, houve crescimento em, aproximadamente, $10 \%$ das placas contendo ágar BHI. Os tubetes de resina que representaram o grupo controle mostraram crescimento discreto em caldo $\mathrm{BHI}$ e em meio Mitis salivarius (Tabela 3). Da mesma maneira, os pincéis pelo Marta que representaram o grupo-controle exibiram turvação em somente um caldo BHI e em ágar BHI (Tabela 4).

$\mathrm{Na}$ análise quali-quantitativa, os grupos caso e controle das seringas de ácido não apresentaram contaminação nas con-

Tabela 1 - Avaliação quali-quantitativa dos pincéis pelo Marta em meios de cultura sólidos (contagem do número de UFCS) e líquido (presença ou ausência de turbidez) - Grupo Caso

\begin{tabular}{cccc}
\hline \hline \multicolumn{4}{c}{ Grupo caso pincel pelo marta $\mathrm{n}^{\circ}$ UFC / área da ponta do pincel } \\
\hline Pincéis & Turvação & Contaminação & Isolamento \\
Pincel 1 & + & $2 \times 10^{3}$ UFC - H.Manitol & Absoluto \\
Pincel 2 & - & - & Absoluto \\
Pincel 3 & - & - & Relativo \\
Pincel 4 & + & $6,3 \times 10^{6}$ UFC - Mitis Salivarius & Relativo \\
Pincel 5 & + & $9,7 \times 10^{6}$ UFC - Ágar BHI & Relativo \\
Pincel 6 & + & $4 \times 10^{3}$ UFC + H.Manitol & Relativo \\
& & $1,6 \times 10^{5}$ UFC - Mitis Salivarius & \\
Pincel 7 & + & $2 \times 10^{4}$ UFC - H.Manitol & Relativo \\
& & $1,6 \times 10^{5}$ UFC - Ágar BHI & \\
Pincel 8 & - & - & Absoluto \\
\hline \hline
\end{tabular}

BATISTA ME

GOMES PS

FREITAS MRLS

ALVAREZ-LEITE ME

AVALIAÇÃO DA

CONTAMINAÇÃO

MICROBIOLÓGICA

DE TUBOS DE

RESINA COMPOSTA,

SERINGAS DE

ÁCIDO E PINCÉIS

DE PELO MARTA

UTILIZADOS EM

DIFERENTES

RESTAURAÇÕES

NA CLÍINICA

ODONTOLÓGICA

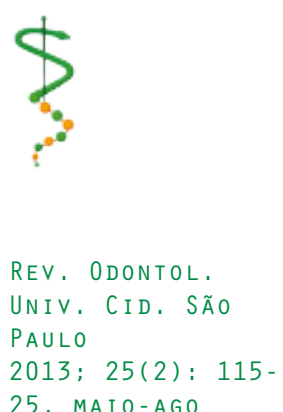


BATISTA ME GOMES PS

FREITAS MRLS ALVAREZ-LEITE ME

AVALIAÇÃO DA

CONTAMINAÇÃO

MICROBIOLÓGICA

DE TUBOS DE

RESINA COMPOSTA,

SERINGAS DE

ÁCIDO E PINCÉIS

DE PELO MARTA

UTILIZADOS EM

DIFERENTES

RESTAURAÇÕES

NA CLINICA

ODONTOLÓGICA

Tabela 2 - Avaliação quali-quantitativa dos tubetes de resina em meios de cultura sólidos (contagem do número de UFCS) e líquido (presença ou ausência de turbidez) Grupo-Caso

Grupo Caso Resina

\begin{tabular}{|c|c|c|c|}
\hline \multicolumn{4}{|c|}{ Grupo Caso Resina } \\
\hline \multicolumn{4}{|c|}{ № UFC / área ponta de rosca até a asa } \\
\hline Resinas & Turvação & Contaminação & Isolamento \\
\hline Resina 1 & + & - & Absoluto \\
\hline Resina 2 & - & - & Absoluto \\
\hline Resina 3 & - & - & Absoluto \\
\hline Resina 4 & - & - & Relativo \\
\hline Resina 5 & + & 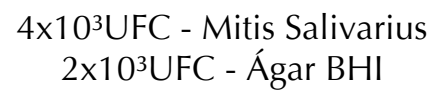 & Relativo \\
\hline Resina 6 & + & $8,6 \times 10^{5}$ UFC - H.Manitol & Relativo \\
\hline Resina 7 & - & - & Relativo \\
\hline Resina 8 & - & - & Relativo \\
\hline Resina 9 & + & $\begin{array}{c}2 \times 10^{3} \text { UFC - Mitis Salivarius } \\
1,6 \times 10^{5} \text { UFC - Ágar BHI }\end{array}$ & Relativo \\
\hline Resina 10 & - & - & Relativo \\
\hline Resina 11 & - & - & Relativo \\
\hline Resina 12 & + & $\begin{array}{c}4 \times 10^{3} \text { UFC - H.Manitol } \\
6 \times 10^{3} \text { UFC - Ágar BHI } \\
2 \times 10^{3} \text { UFC - Mitis Salivarius }\end{array}$ & Relativo \\
\hline Resina 13 & + & $\begin{array}{c}2 \times 10^{3} \text { UFC - Mitis Salivarius } \\
2 \times 10^{3} \text { UFC - Ágar BHI }\end{array}$ & Absoluto \\
\hline
\end{tabular}

Tabela 3 - Avaliação quali-quantitativa dos tubetes de resina em meios de cultura sólidos (contagem do número de UFCS) e líquido (presença ou ausência de turbidez) Grupo-Controle

Grupo controle resina ${ }^{\circ}$ UFC / área ponta de rosca até a asa

\begin{tabular}{ccc}
\hline Resinas & Turvação & $\begin{array}{c}\text { Contaminação } \\
2 \times 10^{3} \cup F C- \\
\text { Mitis Salivarius }\end{array}$ \\
Resina 1 & + & - \\
Resina 2 & - & - \\
Resina 3 & - & - \\
Resina 4 & - & - \\
Resina 5 & - & - \\
Resina 6 & - & - \\
Resina 7 & - & - \\
Resina 8 & - & - \\
Resina 9 & - & - \\
Resina 10 & - & \\
\hline \hline
\end{tabular}

REV, ODONTOL

UNIV, CID, SÃO

PAULO

2013; 25(2): 115 -

25, MAIO-AGO
Tabela 4 - Avaliação quali-quantitativa dos pincéis pelo Marta nos meios de cultura sólidos (contagem do número de UFCs) e líquido (presença ou ausência de turbidez) - Grupo Controle

\begin{tabular}{|c|c|c|}
\hline \multirow{2}{*}{\multicolumn{3}{|c|}{$\begin{array}{l}\text { Grupo controle pincel pelo Marta } \\
\text { NoUFC/área da ponta do pincel }\end{array}$}} \\
\hline & & \\
\hline Pincéis & Turvação & Contaminação \\
\hline Pincel 1 & + & $\begin{array}{c}2 \times 10^{3} \cup F C-\text { Ágar } \\
\text { BHI }\end{array}$ \\
\hline Pincel 2 & - & - \\
\hline Pincel 3 & - & - \\
\hline Pincel 4 & - & - \\
\hline Pincel 5 & - & - \\
\hline \multicolumn{3}{|c|}{ D I SCUSSÃO } \\
\hline \multicolumn{3}{|c|}{$\begin{array}{l}\text { Esta pesquisa comparou a contamina- } \\
\text { ção de materiais utilizados na graduação } \\
\text { do curso de Odontologia por diversos alu- } \\
\text { nos, em pacientes diferentes (grupo-caso) } \\
\text { e os materiais novos (grupo-controle). Me- } \\
\text { todologias semelhantes visando análises } \\
\text { microbiológicas qualitativa e quantitativas }\end{array}$} \\
\hline
\end{tabular}


foram também empregadas em outros experimentos $2,11,14,15$. Os resultados indicaram que, quando o material é manipulado dentro da clínica odontológica, este se encontra passível de adquirir microrganismos indesejáveis que podem gerar o desequilíbrio da microbiota bucal e possibilitar a transmissão de agentes infecciosos. Riscos similares foram ressaltados também nas pesquisas de Almeida e Jorge ${ }^{8}$ (2002) e Pinheiro e Castro ${ }^{9}$ (2009).

No presente estudo, houve crescimento de microrganismos em ágar Mitis salivarius que é recomendado para isolamento de estreptococos orais.

Da mesma maneira, houve crescimento no ágar Hipertônico Manitol, que possui uma concentração muito elevada de cloreto de sódio, utilizado na diferenciação de bactérias do gênero Staphylococcus. Esses microrganismos, além de outras espécies bacterianas foram também identificadas por Almeida et al. ${ }^{13}$ (2010) em tubos de resinas compostas.

Os resultados das análises realizadas permitem esclarecer a importância do cuidado na manipulação dos materiais utilizados na clínica odontológica, já que o índice de contaminação é relevante nos itens do grupo-caso. Tal constatação corrobora trabalhos anteriores que também evidenciam esses resultados ${ }^{2,10}$.

Em relação ao isolamento do campo operatório que consiste numa complementação das medidas que visam à manutenção da cadeia asséptica, observa-se que o isolamento absoluto deve ser preferido sempre que possível, pois possibilita melhor controle do fluxo salivar, diminuindo a presença de contaminação microbiológica durante os procedimentos odontológicos.

Ainda assim e apesar do cuidado na utilização da técnica do isolamento absoluto do campo operatório, eliminando o contato direto com a mucosa do paciente, observou-se, neste estudo, a presença de contaminação. Isso se justifica, pois os fluidos salivares são invisíveis e, caso o isolamento não esteja adequado, é possível que ocorra a presença de fluidos juntamente com a presença de microrganismos. Além disso, os procedimentos odontológicos levam à formação de aerossóis e, por isso, os respingos podem contaminar as luvas do profissional e, consequentemente, os materiais. Conforme alertado por outros autores ${ }^{7,16}$, os artigos podem apresentar agentes infecciosos e o risco potencial de promover infecção cruzada.

A pesquisa mostra que, nas condições testadas, o pincel pelo Marta é o item mais crítico. Importa ressaltar que esse crescimento poderia ser ainda maior, caso os meios fossem incubados em microaerofilia e anaerobiose, pois tais condições são mais favoráveis ao crescimento dos microrganismos da cavidade oral.

Os resultados mostraram, por outro lado, que as seringas de ácido foram os espécimes menos contaminados. A redução ou ausência de crescimento nesses casos se devem, provavelmente, ao ácido fosfórico a $37 \%$ que acidifica o meio e propicia um ambiente desfavorável para o crescimento da maioria dos microrganismos. Verifica-se que $\mathrm{pH}$ em torno da neutralidade, isto é, entre 6,5 e 7,5, é o mais favorável para a maioria dos microrganismos. Alguns microrganismos são favorecidos pelo meio ácido, como as bactérias láticas, certamente porque há inibição da microbiota de competição.

Portanto, ao realizar o atendimento é importante seguir as regras de biossegurança. Para evitar o risco de infecção cruzada, os profissionais e estudantes devem se preocupar com a proteção e a prevenção, preservando a qualidade dos resultados e seguindo criteriosamente as ações voltadas para minimizar os riscos inerentes às atividades realizadas na clínica odontológica ${ }^{17}$. É preciso adotar medidas que diminuam o risco de adquirir e propagar doenças, principalmente as infectocontagiosas.

\section{CONCLUSÕES}

A partir dos materiais e métodos empregados nesta pesquisa, constatou-se que as técnicas de manuseio realizadas na prática odontológica podem provocar a contaminação dos materiais utilizados durante os procedimentos clínicos em dentística restauradora (tubetes de resina e pincéis de pelo Marta) potencializando os riscos de infecção cruzada inerentes a essas atividades.
BATISTA ME

GOMES PS

FREITAS MRLS

ALVAREZ-LEITE ME

AVALIAÇÃO DA

CONTAMINAÇÃO

MICROBIOLÓGICA

DE TUBOS DE

RESINA COMPOSTA,

SERINGAS DE

ÁCIDO E PINCÉIS

DE PELO MARTA

UTILIZADOS EM

DIFERENTES

RESTAURAÇÕES

NA CLÍNICA

ODONTOLÓGICA

\section{3}

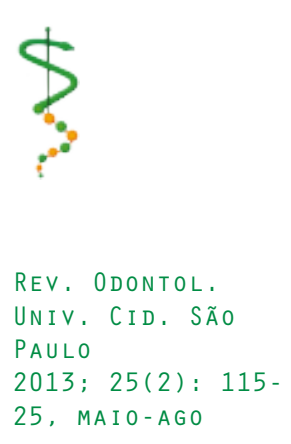


BATISTA ME

GOMES PS

FREITAS MRLS ALVAREZ-LEITE ME

AVALIAÇÃO DA

CONTAMINAÇÃO

MICROBIOLÓGICA

DE TUBOS DE

RESINA COMPOSTA,

SERINGAS DE

ÁCIDO E PINCÉIS

DE PELO MARTA

UTILIZADOS EM

DIFERENTES

RESTAURAÇÕES

NA CLINICA

ODONTOLÓGICA

124
Foi possível observar que o nível de contaminação em seringas para aplicação do ácido durante procedimentos restauradores não apresentou relevância, considerando os métodos e condições utilizados nesta pesquisa.

Os resultados desta pesquisa reforçam a necessidade de cuidados na prestação dos serviços, particularmente aqueles relacionados a uma técnica asséptica. O sucesso no tratamento odontológico está centrado na competência profissional de executar os atendimentos de forma consciente, incluindo regras minuciosas que possibilitem controlar o risco biológico, pois negligenciar as ações de biossegurança é adotar a possibilidade de causar danos ao hospedeiro.

\section{AGRA DEC I MENTO}

As autoras agradecem à Fundação de Amparo à Pesquisa do Estado de Minas Gerais (FAPEMIG), pela oportunidade concedida e pelo apoio financeiro.

\section{REFERÊNCIAS}

1. Lorenzo J. Microbiologia para estudantes de odontologia. São Paulo: Atheneu; 2004.

2. Montenegro G, Dornas KV, Melo MES, Saldanha RR. Contaminação da parte externa dos tubos de resina composta Rev Assoc Paul Cir Dent 2004 jul.-ago. ;58(4):279-82.

3. Baratieri LN. Odontologia restauradora: fundamentos e possibilidades São Paulo: Santos : Quintessence; 2001.

4. Conceição EN. Dentística: saúde e estética São Paulo Artes Médicas; 2000.

5. Alvarez-Leite M, Pereira C. Infecção cruzada em odontologia: prevenção e controle. Belo Horizonte: PUC Minas; 2007.

6. Estrela C, Estrela C. Controle de infecção em odontologia. São Paulo: Artes Médicas; 2003.

7. Jorge AOC. Princípios de biossegurança em odontologia. Rev Biociênc [Periódico on-line].2002; 8(1). Disponível $\mathrm{m}$ : http://periodicos.unitau.br/ojs-2.2/ index.php/biociencias/article/view/60.

8. Almeida KB, Jorge AOC. Avaliação de desinfecção de superfície em cadeira odontológica. 2002 [updated jan.-jun.; Acesso em 1]; 19-27]. Disponível em: http://periodicos.unitau.br/ ojs-2.2/index.php/biociencias/article/ viewFile/53/31.
9. Pinheiro SL, Castro ML. Avaliação da contaminação microbiana do equipamento odontológico e periféricos. Anais do XIV Encontro de Iniciação Científica da PUC-Campinas [Periódico on-line].2009. Disponível m: http://www.puc-campinas.edu.br/websist/portal/pesquisa/ic/pic2009/resumos/2009820_162734_207226670_ res9CE.pdf.

10. Cecchin F, Cecchin L, Wuchryn M, Santos E, Jorge J, Urban V. Estudo do nível de contaminação das superfícies e materiais das clínicas odontológicas da UEPG. Anais do XVIII Encontro Anual de Iniciação Científica [Periódico on-line].2009. Disponível m: http:// www.eaic.uel.br/artigos/CD/3972.pdf.

11. Correia LBLS. Avaliação da contaminação microbiológica da parte externa dos tubos de resina composta utilizados na clínica odontológica [Monografia]. Manaus: Universidade Federal do Amazonas, Curso de Odontologia; 2009.

12. Aleixo RQ, Queiroz RC, Custódio VC, Moura JA. Contaminação dos tubos de resina composta utilizados na clínica odontológica. Clín Pesq Odontol - UNITAU [Periódico on-line].2010; 2(1). Disponível m: http://periodicos. unitau.br/ojs-2.2/index.php/clipeodonto/article/viewFile/966/802. 
13. Almeida JCF, Prado AKS, Silva WC, Pedrosa SF, Moura MAO, Chaves RM, et al. Contaminação de resinas compostas em consultórios odontológicos. ROBRAC 2010 jul.-set.;19(50):

14. Ferraz C, Rocha C, Rocha MMNP, Martins MGA, Jacques P. Contaminação de resinas compostas na prática odontológica. Pesq Bras Odontoped Clin Integr [Periódico on-line].2010; 10(1). Disponível m: http://revista. uepb.edu.br/index.php/pboci/article/ viewFile/813/428.

15. Cardoso CT, Pinto Júnior JR, Pereira EA, Barros LM, Freitas ABDA. Contaminação de tubos de resina composta manipulados sem barreira de proteção. ROBRAC [Periódico on-line].2010; 19(48). Disponível m: http://www.robrac.org.br/seer/index.php/ROBRAC/ article/viewArticle/421.
16. Krieger D, Bueno RE, Gabardo MCL. Perspectivas de biossegurança em odontologia. Rev Gestão Saúde [Periódico on-line].2010; 1(2). Disponível m: http://www.herrero.com.br/revista/ Edicao\%202\%20Artigo\%201.pdf.

17. Pinelli C, Garcia PPNS, Campos JÁDB, Dotta EAV, Rabello AP. Biossegurança e odontologia: crenças e atitudes de graduandos sobre o controle da infecção cruzada. Saude soc [Periódico on-line].2011; 20(2). Disponível m: http://www.scielo.br/scielo. php?script $=$ sci_arttext\&pid=S0104-12902011000200016\&nrm=iso.

Recebido em 01/2013

Aceito em 20/08/2013
BATISTA ME

GOMES PS

FREITAS MRLS

ALVAREZ-LEITE ME

AVALIAÇÃO DA

CONTAMINAÇÃO

MICROBIOLÓGICA

DE TUBOS DE

RESINA COMPOSTA,

SERINGAS DE

ÁCIDO E PINCÉIS

DE PELO MARTA

UTILIZADOS EM

DIFERENTES

RESTAURAÇÕES

NA CLINICA

ODONTOLÓGICA

\section{5}

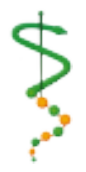

REV. ODONTOL.

UNIV, CID, SÃO

PAULO

2013; 25(2): 115-

25, MAIO-AGO 